\title{
Gender differentials in the social impact of leprosy
}

\author{
S. RAO, V. GAROLE, S. WALAWALKAR, \\ S. KHOT \& N. KARANDIKAR \\ Biometry \& Nutrition Unit, Agharkar Research Institute, Pune-411 \\ 004, India
}

\section{Accepted for publication 22 April 1996}

\begin{abstract}
Summary Prevalence rates of leprosy have reduced considerably in many states where multidrug therapy is in operation. However, reduction in prevalence alone is not sufficient as the social consequences of the diseases on the life of the patient are often severe and persist even after its cure. The present paper, therefore, investigates social impact with special reference to gender differentials. Data obtained from structured questionnaires $(n=606)$ is analysed for this purpose. It was observed that the initial delay in identifying the skin changes as the symptoms of the disease were higher for females ( 29 months) than males (24 months). Even after identifying the symptoms, women were observed to depend exclusively on nonmedical treatment for a longer period (10 months) than males (6 months). Upon starting the medical treatment females were observed to be more compliant than males, but the benefits of regularity appeared to be outweighed by the initial delay in starting medical treatment. The social impact on daily life was more severe for females than males as revealed by the isolation from daily activities, such as, restrictions on participation in familial functions, restrictions on touching children. The paper highlights implications of gender bias on detection and treatment, and suggests modifications for control programmes.
\end{abstract}

\section{Introduction}

The leprosy control programme in India aims to bring down the prevalence of leprosy to below $1 / 10,000$. This is in accordance with the WHO declaration of the global elimination of leprosy by the year $2000 \mathrm{AD}{ }^{1}$ With the introduction of multidrug therapy (MDT), profound changes in the epidemiology of the disease have occurred, ${ }^{12}$ with a significant reduction in the prevalence rates in many states, where MDT is in operation. ${ }^{2}$ However, reduction in prevalence alone is not sufficient as the social consequences of the diseases on the life of the patient are often severe and persist even after its cure. The social aspects associated with this disease are therefore as important, if not more important than the biological ones. 
Leprosy is a highly-stigmatized disease. Misconceptions about leprosy including beliefs that it is contagious, incurable, hereditary or a consequence of a divine punishment, all contribute to stigma in many, though not all societies. The initial acceptance of the disease by an individual and his family is often difficult leading to delay in treatment. Treatment compliance too is affected by several social factors. It is therefore necessary to study the social impact of leprosy in the context of its implications for control programmes.

The social impact of the disease has been described by previous researchers ${ }^{3-5}$ but those investigating gender differentials (gender differences or gender bias) on the social impact of leprosy are scant. ${ }^{11}$ The issue is of considerable significance for women, who are accorded a low social status in many communities in India and receive different treatment from the members in the family and the wider society. In North India it was found $^{6}$ that due to traditional customs, females did not readily come forward for clinical examination and diagnosis, and when they did come the disease was well advanced. Women form a socially vulnerable group. Lack of time, money and mobility are more often causes for poor treatment compliance among female patients. The understanding of gender difference on the social impact of the disease is thus essential in attempting its elimination. In this paper, we highlight the role of gender on the impact of leprosy and hope to demonstrate that the potential for improved disease control could be greatly strengthened by closer attention to gender differences.

\section{Material and methods}

The study was carried out in four districts of Maharashtra and from each district four urban and four tribal or rural sectors were selected. For each sector, a complete list of current and released from treatment (RFT) patients was obtained. Patients marked as left area permanently (LAP), not traceable (NT) and released from control (RFC) were not included in the sampling frame. A stratified random sample was then selected using age, gender and deformity status as the main strata. Patients above the age of 18 were included in the study as younger patients are unlikely to experience any significant social impact on issues like marriage or job.

Data was collected using a structured questionnaire which included questions seeking information on personal demographic variables (age, gender, type of family, native place, educational status, marital status, etc.); the details of disease status at detection; reactions of self, family members and others on detection; treatments sought for treating the disease with reasons; treatment given by family members in day-to-day life, participation in social life, etc. The questionnaires, after appropriate field testing, were used for data collection and were filled in by interviewing the patients.

Each interview was carried out over 2 to 3 visits, i.e. initial visit often sought information on personal demographic variables and disease status at detection, while more sensitive questions were tackled in subsequent visits, once a rapport was established. Tape recorders were used with the full consent of respondents and were useful for the collection of everything said by the patient during his/her interview. The interview was carried out maintaining privacy and confidentiality. Data obtained from 606 questionnaires were analysed for the purpose of the present study.

Some of the operational definitions need to be mentioned before proceeding for 
analysis of data. The joint family is considered as one in which married sons along with their wives are also staying with the parents who are heads of households. Whereas a nuclear family is one in which only the married couple and their children are staying. The sample consists of 'old' patients and 'new' patients. While old patients are from colonies and homes; detected on an average 10 years previously, the 'new' patients are those currently on treatment or under surveillance and detected during the last 5 years. All treatments other than medical, sought by the patient are referred to as 'nonformal' treatment. This includes religious treatments, fasting, offerings and the treatment given by the traditional healers. Deformity grades are as per WHO norms, i.e. zero (no anaesthesia, no visible deformity or damage), grade I (anaesthesia present but no visible deformity or damage), and grade II (visible deformity or damage present). Irregularity in treatment is considered when treatment of a patient is not completed even within the maximum stipulated time span, i.e. 9 months for paucibacillary (PB) patients and 36 months for multibacillary (MB) patients.

\section{Results}

Age-gender distribution of patients in the study is given in Table 1. The current patient in the study sample are about $77 \%$, while the remaining $23 \%$ were old patients, mostly from colonies and leprosy homes. The comparison of the two groups is useful in examining the changes that may have occurred over the years with regard to social impact of the disease.

\section{SOCIOECONOMIC STATUS}

The lower social status of females in India and typical of many cultures, may result in greater suffering among women. It is also likely that the lower social status in itself may contribute to gender differences in the detection and treatment of this disease. The socioeconomic characteristics of the study population are, described separately for males and females (Table 2). It can be observed that the proportion of illiterate female patients is significantly higher, while the proportion of employed females is significantly lower compared to males, indicating a low social status of many female patients. We also observe in the same table, that family type at detection and at present shows considerable change. It appears that after the detection, patients perhaps come out of the joint

Table 1. Age-gender distribution of patients in the study

\begin{tabular}{lrccc}
\hline Age $($ yr $)$ & \multicolumn{1}{c}{ Male } & Female & Total \\
\hline $18-30$ & $71(24 \cdot 5)$ & $76(24 \cdot 0)$ & $147(24 \cdot 3)$ \\
$30-50$ & 133 & $(45 \cdot 9)$ & $174(55 \cdot 1)$ & $307(50 \cdot 6)$ \\
$50+$ & 86 & $(29 \cdot 6)$ & $66(20 \cdot 9)$ & $152(25 \cdot 1)$ \\
Total & 290 & 316 & 606 \\
Current patients & $242(83 \cdot 4)$ & $224(70 \cdot 9)$ & $466(76 \cdot 9)$ \\
\hline
\end{tabular}

Figures in parentheses represent percentages. 
Table 2. Socioeconomic profile of patients in the study

\begin{tabular}{|c|c|c|c|}
\hline Variable & & $\begin{array}{c}\text { Males } \\
(n=279)\end{array}$ & $\begin{array}{l}\text { Females } \\
(n=311)\end{array}$ \\
\hline \multicolumn{4}{|l|}{ Area } \\
\hline Rural & & $41 \cdot 4$ & $56 \cdot 0$ \\
\hline Urban & & $16 \cdot 9$ & $18 \cdot 4$ \\
\hline Tribal & & $41 \cdot 7$ & $25 \cdot 6$ \\
\hline \multicolumn{4}{|l|}{ Family type } \\
\hline \multirow[t]{2}{*}{ at detection } & Joint & $42 \cdot 6$ & $37 \cdot 0$ \\
\hline & Nuclear & $49 \cdot 7$ & $60 \cdot 5$ \\
\hline \multirow{2}{*}{ at present } & Joint & $25 \cdot 4$ & $20 \cdot 1$ \\
\hline & Nuclear & $66 \cdot 7$ & $64 \cdot 3$ \\
\hline \multicolumn{4}{|c|}{ Family position as Head } \\
\hline \multirow{2}{*}{\multicolumn{2}{|c|}{$\begin{array}{l}\text { at detection } \\
\text { at present }\end{array}$}} & $57 \cdot 6$ & $4 \cdot 8$ \\
\hline & & $69 \cdot 9$ & $6 \cdot 4$ \\
\hline \multirow{2}{*}{\multicolumn{2}{|c|}{$\begin{array}{l}\% \text { illiterate } \\
\% \text { married }\end{array}$}} & $44 \cdot 1$ & $74 \cdot 3$ \\
\hline & & $78 \cdot 5$ & $70 \cdot 1$ \\
\hline \multicolumn{2}{|l|}{$\%$ employed } & $75 \cdot 3$ & $49 \cdot 5$ \\
\hline \multicolumn{2}{|l|}{$\%$ deformed } & $13 \cdot 4$ & $9 \cdot 0$ \\
\hline
\end{tabular}

families and stay in nuclear families as shown by a reduction in the proportion of joint family status at present, compared to that at detection.

In a study from South India, it has been reported that a diagnosis of leprosy has resulted in the break-up of joint families. ${ }^{3}$ The position of the patient in the family, however, shows significant gender differences. Thus only a negligible proportion of females in contrast to males happen to be head of a family, indicating that most women are likely to be deprived of decision-making power.

\section{KNOWLEDGE AND TREATMENT SEEKING}

One of the major factors that adversely affects the control programme is the delay in treatment. Lack of knowledge about disease causation and its treatment influences the course of the disease. Gender differences with regard to knowledge and health-seeking behaviour are thus important and are brought out in Table 3. It can be observed that fewer new patients considered 'sin' as a cause of their disease compared to old patients suggesting that knowledge about disease causation has improved over the years. It is interesting to note that this change is seen more among females (reduction from $43 \%$ to $24 \%$ ) than males.

The knowledge gained about the causation of the disease, however, has not necessarily helped females in reducing the delay in seeking the treatment. It can be seen that the delay in detecting the changes occurring on the skin as initial symptoms of disease is significantly higher for females ( 31 months) than that for males (16.8 months) in the case of old patients. Although this delay has dropped considerably among new patients, it is still higher for females (by about 5 months) compared to male patients. Thus even today a considerable time elapses in identifying the initial symptoms of the disease and this is detrimental to early detection. Clearly, imparting knowledge about identifying the initial symptoms of the disease is needed. 
Table 3. Knowledge and health seeking behaviour of male and female patients

\begin{tabular}{|c|c|c|c|}
\hline Variable & Patients* & Males & Females \\
\hline Cause of disease as $\sin (\%)$ & $\begin{array}{l}\text { Old } \\
\text { New }\end{array}$ & $\begin{array}{l}30 \cdot 5 \\
29 \cdot 2\end{array}$ & $\begin{array}{l}43 \cdot 1 \\
24 \cdot 7\end{array}$ \\
\hline Gap 1 (months) $\dagger$ & $\begin{array}{l}\text { Old } \\
\text { New }\end{array}$ & $\begin{array}{l}16 \cdot 8 \\
13 \cdot 8\end{array}$ & $\begin{array}{l}30 \cdot 9 \\
18 \cdot 5\end{array}$ \\
\hline Gap 2 (months) $\ddagger$ & $\begin{array}{l}\text { Old } \\
\text { New }\end{array}$ & $\begin{array}{l}24 \cdot 4 \\
10 \cdot 8\end{array}$ & $\begin{array}{l}32 \cdot 9 \\
13 \cdot 5\end{array}$ \\
\hline Total delay in treatment (months) & $\begin{array}{l}\text { Old } \\
\text { New }\end{array}$ & $\begin{array}{l}41 \cdot 2 \\
24 \cdot 6\end{array}$ & $\begin{array}{l}63 \cdot 8 \\
32 \cdot 0\end{array}$ \\
\hline Irregularity in treatment (months) & $\begin{array}{l}\text { Old } \\
\text { New }\end{array}$ & $\begin{array}{l}30 \cdot 0 \\
16 \cdot 7\end{array}$ & $\begin{array}{r}16 \cdot 4 \\
5 \cdot 0\end{array}$ \\
\hline $\begin{array}{l}\text { Exclusive dependence on } \\
\text { traditional treatment (months) }\end{array}$ & $\begin{array}{l}\text { Old } \\
\text { New }\end{array}$ & $\begin{array}{r}21 \cdot 5 \\
6 \cdot 4\end{array}$ & $\begin{array}{r}25 \cdot 5 \\
9 \cdot 7\end{array}$ \\
\hline $\begin{array}{lcc}\text { * Sample size for } & \text { M } & \text { F } \\
\text { old patients } & 28 & 56 \\
\text { new patients } & 151 & 129 \\
\text { † Gap 1 indicates delay in identi } \\
\text { † Gap } 2 \text { indicates delay betwe } \\
\text { treatment. }\end{array}$ & $\begin{array}{l}\text { change } \\
\text { diagnosi }\end{array}$ & $\begin{array}{l}\text { as sym } \\
\text { cosy a }\end{array}$ & $\begin{array}{l}\text { f disease. } \\
\text { ting the }\end{array}$ \\
\hline
\end{tabular}

Even after identif ying the symptoms of the disease there is likely to be a further delay in receiving the formal treatment owing to differences in the health-seeking behaviours of male and female patients. Very often women delayed taking treatment until they had undertaken measures such as fastings and offerings to God. Gap 2 in Table 3 gives the estimates of this delay and it can be seen that for female patients (old as well as new) these values are higher than those for males. The total delay in initiating the formal treatment was thus as high as 32 months even for new female patients compared to 24 months for male patients. One of the major reasons was observed to be the exclusive dependence of female patients on nonformal treatments, i.e. religious approaches or the treatment given by traditional healers, in the initial stage of the disease.

In a study ${ }^{7}$ among Pakistani patients it was observed that many patients had lost years of effective treatment as a result of opting for nonformal treatments. Second, it was also observed that relatively more women $(26 \%)$ compared to men $(21 \%)$ tend to hide the disease, mainly because of the fear of social stigma or the fear of dehabilitation $(9 \%$ vs $6.4 \%$ ). Thus delays in treatment could be higher in illiterate women of poor communities from less urbanized areas where the disease prevails. The understanding of gender differences in health seeking is therefore, critical in the context of control programme.

On initiation of the treatment however, more females appeared to be regular than males in both the groups of old and new patients. Higher compliance among females is likely to be due to the known fact that they are socialized to conform to prescribed behaviour. It is, however, feared that benefits of regularity in treatment are perhaps outweighed by the considerable delay in initiating the formal treatment soon after detection. 
IMPACT ON DAILY LIFE

Women with leprosy face definite social and psychological problems irrespective of their socioeconomic status. The degree to which men and women leprosy patients were isolated from their family activities and events is shown in Table 4. Among those who openly responded to the question on isolation/restriction imposed by family members, it was observed that by and large women were more isolated from all activities than men. Most women $(80 \%)$ were isolated from their major daily task of cooking food for everyone. It was probably the fear of contaminating others that isolated them from their daily activities. In fact one study ${ }^{5}$ found that discriminative attitudes and fear of spreading infection are more common in joint families. Isolation from touching others was again a strong reaction that many women $(84 \%)$ faced, unlike men $(17 \cdot 7 \%)$. Loss of freedom to touch and to be touched, especially with their children, symbolized rejection. Similarly, they were isolated from sleeping in the same room along with the other family members (if unmarried) or with their spouses (if married). Finally, more women suffered from isolation in attending the festival celebrations in their own family among women than men. Such isolation from vital domestic roles develops among women a self-image of being a useless member of the family. ${ }^{8}$

It has been previously observed ${ }^{9}$ that prejudice is shown not only by neighbours and relatives but by the immediate family as well. Strained intrafamilial relationships have also been observed. ${ }^{4}$ However, in describing the social impact of the disease neither of these commented on the gender differences.

Table 4. Impact of disease affliction* on dayto-day life

\begin{tabular}{lcc}
\hline Variable & $\begin{array}{c}\text { Males } \\
(\%)\end{array}$ & $\begin{array}{c}\text { Females } \\
(\%)\end{array}$ \\
\hline Isolated from: & & \\
$\quad$ cooking & 29.0 & 80.0 \\
touching others & $17 \cdot 7$ & 84.0 \\
eating together & 48.0 & 63.0 \\
sleeping together & 20.0 & 85.8 \\
sex & 22.0 & $71 \cdot 0$ \\
attending festivals & 9.6 & 21.0 \\
\hline
\end{tabular}

* Trends for old and new patients were almost similar and hence given as pooled data.

\section{INTERACTION WITH COMMUNITY}

Family influence and pressures are known to act as a powerful force determining a significant portion of observed and reported behaviours of patients. ${ }^{7}$ The disease not only affects day-to-day functioning in the family, but considerable restrictions are enforced on patients due to the fear of social stigma. As can be seen from Table 5, more women seem to have these restrictions than men. For example, $30 \%$ of women reported constraints on social outings with the family and travelling. Attending festival 
Table 5. Impact of leprosy on social life

\begin{tabular}{lcc}
\hline Variable & $\begin{array}{c}\text { Males } \\
(\%)\end{array}$ & $\begin{array}{c}\text { Females } \\
(\%)\end{array}$ \\
\hline Ref rained from: & & \\
$\quad$ going out & $10 \cdot 5$ & $27 \cdot 8$ \\
travelling & $10 \cdot 5$ & $30 \cdot 8$ \\
attending festivals & $10 \cdot 0$ & $17 \cdot 9$ \\
going to the temple & $33 \cdot 3$ & $13 \cdot 3$ \\
attending marriages & $15 \cdot 4$ & $13 \cdot 0$ \\
\hline
\end{tabular}

celebrations in the neighbourhood was also prohibited for women $(17 \cdot 9 \%)$ but only $10 \%$ for men. Male and female patients experienced somewhat similar restrictions regarding participation in marriages in the community. Thus, although men and women were both affected in terms of their social life, women suffered more isolation and rejection from family and society. Such restrictions clearly reduce the mobility of women patients even more, and affect their treatment.

\section{PERCEIVED GENDER DIFFERENCES}

Men and women patients were asked about their own perception of gender differences with regard to several important issues which have exerted a strong impact on the treatment of their disease and in turn on their lives. Almost all women $(85 \%)$ felt that gender was definitely responsible for the delay in the detection of their disease and a significant proportion of men $(67 \%)$ agreed to this opinion. Similar was the perception with regard to access to medical treatment. While $67 \%$ of females felt that gender bias affected their access to treatment only $54 \%$ males felt so. The familial support too was felt to be biased by $67 \%$ women while only $46 \%$ consented to this opinion. The disadvantages of gender bias to women on daily life were perceived in fact by more men $(72 \%)$ than women $(68 \%)$ themselves. In most instances, such as humiliation or insulting treatment, the impact on social life and sharing familial property the majority of patients agreed that gender differences do significantly affect women's lives and hence the course of disease. In case of marriage too, more men $(82.5 \%)$ than women

Table 6. Perception of patients about gender bias

\begin{tabular}{lcc}
\hline Perceived gender differences in & Males (\%) & Females (\%) \\
\hline Delay in detection & $67 \cdot 1$ & $85 \cdot 0$ \\
Access to medical treatment & $54 \cdot 3$ & $67 \cdot 2$ \\
Support of family & $46 \cdot 6$ & $67 \cdot 4$ \\
Impact on daily life & $72 \cdot 3$ & $68 \cdot 3$ \\
Impact on social life & $61 \cdot 2$ & $65 \cdot 0$ \\
Marriage prospects & $82 \cdot 5$ & $58 \cdot 6$ \\
Difficulty in going to clinic & $51 \cdot 4$ & $58 \cdot 6$ \\
Insulting treatment by family members & $75 \cdot 6$ & $73 \cdot 9$ \\
Share in familial property & $83 \cdot 7$ & $95 \cdot 6$ \\
\end{tabular}


$(58 \cdot 6 \%)$ recognized the disadvantages to females. Thus although relatively few patients responded to their perceptions and observations about gender bias, most agreed to its existence as well as its influence on various facets of life.

\section{Discussion}

While women bear more social and cultural responsibilities for maintaining the family in communities of many developing countries, their real situation is often characterized by extreme dependency and discrimination in every aspect of their lives. The empirical evidence presented in this study demonstrates the importance of analysing the situation of leprosy patients from the gender perspective as it has significant implications for disease control.

Important gender differences were apparent on the social impact of the disease. While both men and women were negatively affected in most situations, the extent of the impact was more in case of women than men.

Delay in initiating the formal treatment was longer in the case of women than men. This was partly due to the lack of knowledge about identifying the initial symptoms of the disease, but a more important factor was the dependence on religious or traditional treatment. The suggestion is that the educational component needs to be strengthened in order to reach masses of women in India. Religious beliefs need to be taken into account while imparting knowledge about the medical treatment of the disease. Perhaps groups such as Women's Clubs (which exist in every village), women school teachers or women members of Panchayat (local village government) can be involved for educating women as well as community.

The personal interaction of the leprosy worker with the patient while delivering the drugs can play an important role. He could explain the benefits of early treatment and also encourage regular treatment and if appropriate mention the consequences of incomplete treatment, delayed treatment, and irregularity. Additionally, in the case of women patients a dialogue with a family member often accompanying her would help to reduce the familial stigma. Counselling, especially with the spouse would be beneficial.

Inadequate knowledge on the part of physicians has been observed to result in misdiagnosis or mismanagement leading to loss of years of potentially effective therapy. ${ }^{7}$ Education of traditional healers by trained physicians would make an additional vital impact. Short-term courses could be planned to train local traditional healers to identify early symptoms of the disease and subsequent referral, so that early detection of women patients is feasible. Involving females as leprosy workers or as counsellors would also be of great help. Similarly, educating health personnel in other programmes such as maternal child health $(\mathrm{MCH})$ or those in primary health care $(\mathrm{PHC})$ in fact would prove beneficial.

One study ${ }^{10}$ reported that women experienced problems if they had Grade II deformity and that the situation has improved in recent years. Their study, however, lacks comparable data on male patients and it therefore does not highlight gender differences. It was observed in this study that although men and women both experienced the social impact of the disease, women suffered more isolation and rejection from family and society. The need to reduce social stigma is again emphasized, as it is the root 
cause of hiding the disease and this results in delayed treatment. The educational programme will highlight the effectiveness of MDT and give confidence to patients and their families that the disease is curable if diagnosed early and treated regularly. This message about effectiveness of MDT can reach the masses by using a variety of media and methods.

The patient's perception about gender bias was studied in a small sample of men and women. It was interesting to note that women tend to suffer in silence and were conservative in agreeing to the disadvantages due to gender bias. In contrast, men agreed more openly to the existence of gender bias and its disadvantages to women patients.

\section{Conclusion}

Gender bias has important implications for detection, treatment and hence control of the disease. This bias needs to be brought to the attention of programme managers, medical doctors, technicians and others in control programmes. The control programme could be suitably modified with regard to various activities, i.e. survey, education and treatment with due consideration to gender bias. The evidence from this study strongly suggests that attention to the disadvantaged situation of women with leprosy will greatly increase case detection or presentation, treatment and case management, not only in India but also in other countries.

\section{Acknowledgments}

This investigation received financial support from the UNDP/World Bank/WHO Special Programme for Research and Training in Tropical Diseases (TDR). We duly acknowledge this financial support of TDR. We are also thankful to Dr A. D. Agate, Director, Agharkar Research Institute, Pune for providing necessary facilities to carry out these investigations. Finally, thanks are also due to health personnel, especially leprosy technicians and our field investigators Mr Uday Gaikwad and Mr Vijay Suryagan for data collection.

\section{References}

1 Fourty Fourth Session, World Health Assembly, 1991.

2 Mittal BN. National strategy for elimination of leprosy in India, Ind J Lepr, 1992; 65: 513-20.

3 Ramu G, Dwiwedi MP, Iyer CGS. Social reaction to leprosy in a rural population in Chingleput District (Tamilnadu) Lepr in India, 1975; 43(3): 156-69.

${ }^{4}$ Kant VP. Socio-economic problems of leprosy patients: and their relatives in Gujarat state. Ind J Lepr, 1984; 56: 889-99.

5 Kaur H, Ramesh V. Social problems of women leprosy patients: a study conducted at two urban leprosy centers in Delhi. Lepr Rev, 1994; 65: 361-75.

${ }^{6}$ Nakai E. Leprosy in Northern India-An epidemiological study in Ghatempur Block. Jap J Lepr, 1980; 49: 77-86.

7 Mull JD, Wood SC, Gans LP, Mull SD. Culture and compliance among leprosy patients in Pakistan. Soc Sci Med, 1989; 29(7): 799-811.

8 Vlassoff C, Bonilla E. Gender differences in the determinants and consequences of tropical diseases: What do we know? J Bio Sci, 1994; 26(1): 37-53. 
${ }^{9}$ Kushawas SS, Govila AK, Upadhyay S, Kushawas J. A study of social stigma among leprosy patients attending a leprosy clinic in Gwalior. Lepr Ind, 1981; 53: 221-25.

10 Naik SS, Hambarde PS, Desai AN. Problems and needs of women leprosy patients in Bombay in Goa-A preliminary report. Ind J Le pr, 1991; 63(2): 213-22.

11 Rathgeber E, Vlassoff C. Gender and tropical diseases: A new research focus. Soc Sci Med, 1993; 37(4): 513-20.

12 Ulrich M, Zuluetta AM, Caceres-Dittmar G, Sampson C, Pinardi ME, Rada EM, Aranau N. Leprosy in women: Characteristics and repercussions. Soc Sci Med, 1991; 32(4): 445-56. 